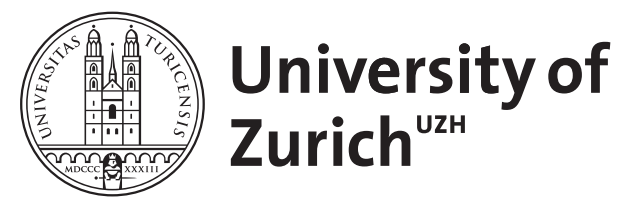

\title{
Site-Specific Dual-Color Labeling of Long RNAs
}

Zhao, Meng ; Börner, Richard ; Sigel, Roland K O ; Freisinger, Eva

\begin{abstract}
Labeling of large RNAs with reporting entities, e.g., fluorophores, has significant impact on RNA studies in vitro and in vivo. Here, we describe a minimally invasive RNA labeling method featuring nucleotide and position selectivity, which solves the long-standing challenge of how to achieve accurate site-specific labeling of large RNAs with a least possible influence on folding and/or function. We use a custom-designed reactive DNA strand to hybridize to the RNA and transfer the alkyne group onto the targeted adenine or cytosine. Simultaneously, the 3 -terminus of RNA is converted to a dialdehyde moiety under the experimental condition applied. The incorporated functionalities at the internal and the 3 -terminal sites can then be conjugated with reporting entities via bioorthogonal chemistry. This method is particularly valuable for, but not limited to, single-molecule fluorescence applications. We demonstrate the method on an RNA construct of 275 nucleotides, the btuB riboswitch of Escherichia coli.
\end{abstract}

DOI: https://doi.org/10.1007/978-1-0716-0231-7_16

Posted at the Zurich Open Repository and Archive, University of Zurich

ZORA URL: https://doi.org/10.5167/uzh-186967

Book Section

Accepted Version

Originally published at:

Zhao, Meng; Börner, Richard; Sigel, Roland K O; Freisinger, Eva (2020). Site-Specific Dual-Color Labeling of Long RNAs. In: Heise, Tilman. RNA Chaperones. New York: Springer, 253-270.

DOI: https://doi.org/10.1007/978-1-0716-0231-7_16 


\section{Site-specific dual-color labeling of long RNAs}

Meng Zhao†, Richard Börner, Roland K.O. Sigel*, Eva Freisinger*

Department of Chemistry, University of Zurich, 8057 Zurich, Switzerland

* To whom correspondence should be addressed. Tel: +41 (0)44 65635 4621; Fax: +41

(0)44 635 6802; Email: freisinger@chem.uzh.ch. Correspondence may also be addressed

to. Tel: +41 (0)44 65635 4652; Fax: +41 (0)44 635 6802; Email: roland.sigel@chem.uzh.ch.

† Present Address: Meng Zhao, Department of Physics, University of Alberta, Edmonton, AB T6G 2E1, Canada

\section{ABSTRACT}

Labeling of large RNAs with reporting entities, e.g. fluorophores, has significant impact on RNA studies in vitro and in vivo. Here we describe a minimally invasive RNA labeling method featuring nucleotide- and position-selectivity, which solves the long-standing challenge of how to achieve accurate site-specific labeling of large RNAs with a least possible influence on folding and/or function. We use a custom-designed reactive DNA strand to hybridize to the RNA and transfer the alkyne group onto the targeted adenine or cytosine. Simultaneously, the 3'-terminus of RNA is converted to a di-aldehyde moiety under the experimental condition applied. The incorporated functionalities at the internal and the 3'terminal sites can then be conjugated with reporting entities via bioorthogonal chemistry. This method is particularly valuable for, but not limited to, single-molecule fluorescence applications. We demonstrate the method on an RNA construct of 275 nucleotides, the btuB riboswitch of Escherichia coli.

Key words: long RNAs, site-specific labeling, orthogonal chemistry, riboswitch, singlemolecule fluorescence resonance energy transfer (smFRET) 


\section{Introduction}

Labeling of long RNAs remains challenging due to the lack of a universally applicable method that allows the conjugation of reporting entities in an orthogonal, yet site-specific manner. Existing methods suffer from either the exponentially reduced labeling efficiency with increasing RNA size or the disruption of the correct fold and thus function of the RNA [1-11]. Here, we describe a post-transcriptional labeling method [12] that employs a customized DNA oligonucleotide as reactive strand (dRS) to transfer an alkyne group on any adenine or cytosine residue within an RNA strand of arbitrary length [13, 14]. To increase the yield of this chemical reaction, we make use of DNA oligonucleotides as helper sequences (dHSs) preventing secondary structure formation and increasing the accessibility of the target site [15]. In this one-pot reaction the 3'-terminal ribose ring is concomitantly opened to a di-aldehyde moiety [16] leading to the functionalized RNA with an internal alkyne and a reactive 3'-terminal end, which allows for bioorthogonal chemistry without cross-reactivity. We use the two carbocyanine dyes Cy3-hydrazide for coupling to the 3'-terminal di-aldehyde moiety and Cy5-azide for reaction with the internal-alkyne unit, to obtain a dual-color labeled btuB riboswitch RNA of 275 nt $[17,18]$. The labeled construct is used for single-molecule fluorescence resonance energy transfer (smFRET) studies [12] as an example but the presented method can be adapted for any technique that requires labelling of RNAs without restriction in size and fold.

\section{Materials}

If not stated otherwise, chemicals were obtained in highest commercially available grades from Sigma-Aldrich/Merck (Buchs, Switzerland) and used without further purification. All buffers were prepared with ultrapure water (Thermo Fisher Scientific water purification systems) and filtered before use. Solutions and chemicals are kept at room temperature unless indicated otherwise. DNA oligonulceotides were purchased from IBA (Göttingen, Germany). Carbocyanine fluorophores were purchased from Lumiprobe (Hannover, Germany) and always protected from light. 


\subsection{Organic solvents and agents}

1. DMSO (purum).

2. DMF (purum).

3. Ethanol (EtOH, 100\%).

4. Acetone (purum).

5. Reactive group precursor (Fig. 1a), synthesized as described in [14].

6. N-Hydroxysuccinimide (NHS).

7. N, N'-Dicyclohexylcarbodiimide (DCC).

8. 2,2'-Pyridine disulfide (PDS): 1.6 M in DMSO.

9. 4-Dimethylaminopyridine (DMAP): 1.2 M in DMSO.

10. Triphenylphosphine $\left(\mathrm{PPh}_{3}\right): 1.2 \mathrm{M}$ in DMF.

11. Ethylene diamine (purum).

12. Formamide (purum).

13. Lithium perchlorate $\left(\mathrm{LiClO}_{4}\right): 2 \%(w / v)$ in acetone.

14. Ethylenediaminetetraacetic acid (EDTA).

15. Xylene cyanole.

16. Bromophenol blue.

17. Tris(benzyltriazolylmethyl)amine (TBTA).

18. Copper(II) sulfate (CuSO4).

19. Acrylamide/bisacrylamide solution (30\%)

20. Urea

2.2 Buffers and solutions 
1. Potassium phosphate buffer: $100 \mathrm{mM}, \mathrm{pH} 7.5$.

2. Sodium acetate $(\mathrm{NaOAc})$ buffer $(50 \times, 1 \times): 1.0 \mathrm{M}, 20 \mathrm{mM}$ in water, $\mathrm{pH} 5.5$.

3. Triethylammonium acetate (TEAA) buffer: $0.5 \mathrm{M}, \mathrm{pH} 7.0$.

4. Soaking buffer: $10 \mathrm{mM}$ MOPS, $1.0 \mathrm{mM}$ EDTA and $250 \mathrm{mM} \mathrm{NaCl}, \mathrm{pH}$ 6.0.

5. Folding buffer $(5 \times)$ : $330 \mathrm{mM}$ HEPES, $200 \mathrm{mM}$ Tris- $\mathrm{HCl}$ and $250 \mathrm{mM} \mathrm{KCl,} \mathrm{pH} \mathrm{7.5.}$

6. Running buffer $(1 \times)$ : $66 \mathrm{mM}$ HEPES, $34 \mathrm{mM}$ Tris-HCl and $3.0 \mathrm{mM} \mathrm{MgOAc}, \mathrm{pH}$ 7.5.

7. Tris-borate-EDTA (TBE, $10 \times$ ) buffer, Thermo Fisher Scientific.

8. Formamide loading buffer (FLB): $82 \%(\mathrm{v} / \mathrm{v})$ formamide, $10 \mathrm{mM}$ EDTA, $0.16 \%(\mathrm{w} / \mathrm{v})$ xylene cyanole and $0.16(\mathrm{w} / \mathrm{v})$ bromophenol blue.

9. Cetyltrimethylammonium bromide (CTAB): $8 \%(w / v)$ in water.

10. Sodium chloride $(\mathrm{NaCl}): 3.0 \mathrm{M}$ in water.

11. Sodium periodate $\left(\mathrm{NaIO}_{4}\right): 20 \mathrm{mM}$, in $\mathrm{NaOAc}$ buffer $(1 \times)$.

12. Ethylene glycol: $15 \mathrm{mM}$, in NaOAc buffer $(1 \times)$

13. Ascorbic acid: $5.0 \mathrm{mM}$ in water.

14. $\mathrm{MgCl}_{2}: 30 \mathrm{mM}$ in water.

15. $\mathrm{KCl}: 1.0 \mathrm{M}$ in water

16. Cu-TBTA solution: $10 \mathrm{mM} \mathrm{CuSO}_{4}$ and $10 \mathrm{mM}$ TBTA in 55\% (v/v) DMSO/water.

\subsection{Deoxyribonucleotide triphosphate (dNTP), DNA oligonucleotides and RNA}

1. $\mathrm{dNTP}_{\text {mix: }} 10 \mathrm{mM}$, New England Biolabs

2. Guide-DNA (Fig. 1b) solution: $4.0 \mathrm{mM}$ in water.

3. Helper sequence (dHS) solution: $100 \mu \mathrm{M}$ in water.

4. 5'-32P-labeled DNA primer ( ${ }^{32} \mathrm{P}-$ primer): $1.0 \mu \mathrm{M}$ in water, prepared as described in [19]. ${ }^{32} \mathrm{P}$ Y-ATP was purchased from PerkinElmer (Schwerzenbach, Switzerland).

5. Biotin-tagged DNA oligonucleotides: $1 \mu \mathrm{M}$ in water. 
6. The modified btuB riboswitch RNA was designed for smFRET immobilization studies according to the literature [12]. In vitro RNA transcription was performed with homemade T7 polymerase [20].

\subsection{Fluorophores}

1. Cyanine3 hydrazide (Cy3-hydrazide): $10 \mathrm{mM}$ in DMSO.

2. Sulfo-Cyanine5 azide (Cy5-azide): $10 \mathrm{mM}$ in DMSO.

\subsection{Kits and columns}

1. AMV reverse transcriptase kit: enzyme in glycerol $(2 \mathrm{U} / \mu \mathrm{L})$, enzyme buffer $(4 \times)$ and RNase

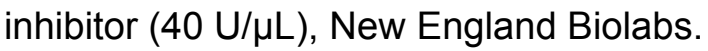

2. SuperScript III reverse transcriptase kit: enzyme in glycerol $(20 \mathrm{U} / \mu \mathrm{L})$, enzyme buffer $(4 \times)$

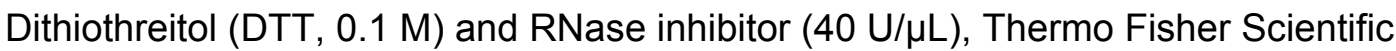
3. NAP-5 desalting column, GE Healthcare.

\subsection{Poly acrylamide gel electrophoreses (PAGE) gel}

1. $5 \%, 10 \%$ and $18 \%$ denaturing PAGE: TBE buffer $(1 \times), 7 \mathrm{M}$ urea and $5 \%, 10 \%$ and $18 \%$ $(w / v)$ acrylamide/bisacrylamide.

2. $6 \%$ native PAGE: running buffer $3 \mathrm{mM} \mathrm{MgOAc}, 66 \mathrm{mM}$ HEPES and $34 \mathrm{mM}$ Tris- $\mathrm{HCl}$, $\mathrm{pH}$ $7.5,6 \%(\mathrm{w} / \mathrm{v})$ acrylamide/bisacrylamide.

\section{Methods}

\subsection{Preparation of the reactive group, Solution I}

1. Weigh $3.1 \mathrm{mg}$ of reactive group precursor (Fig. 1a see Note 1) and $1.5 \mathrm{mg}$ of NHS in a $1.5 \mathrm{~mL}$ tube and dissolve it in $80 \mu \mathrm{L}$ DMF. Weigh $2.7 \mathrm{mg}$ of DCC in another $1.5 \mathrm{~mL}$ tube and dissolve it in $20 \mu \mathrm{L}$ DMF. Mix both solutions together and incubate the mixture at room temperature and 500 rpm overnight (see Note 2).

2. Centrifuge the mixture at $4{ }^{\circ} \mathrm{C}$ and $16.1 \times 10^{3} \mathrm{rfc}$ for $10 \mathrm{~min}$. Collect the supernatant which contains the activated reactive group in a clean $1.5 \mathrm{~mL}$ tube and keep it on ice (see Note 3). Referred to as Solution I. 


\subsection{Preparation of the ethylene diamine-modified guide-DNA, Solution II}

1. Prepare $25 \mu \mathrm{L}$ of the guide-DNA (see Note 4) solution in a $1.5 \mathrm{~mL}$ tube and add $6.0 \mu \mathrm{L}$ of CTAB solution (see Note 5). Mix gently and incubate at room temperature and $500 \mathrm{rpm}$ for $30 \mathrm{~min}$. Centrifuge at room temperature and $16.1 \times 10^{3} \mathrm{rfc}$ for $30 \mathrm{~min}$. Remove and discard the supernatant and dry the precipitate in vacuum for $10 \mathrm{~min}$. Dissolve the remaining pellet in $50 \mu \mathrm{L}$ DMSO.

2. Mix $50 \mu \mathrm{L}$ of PDS (see Note 6), $50 \mu \mathrm{L}$ of DMAP and $50 \mu \mathrm{L}$ of $\mathrm{PPh}_{3}$ solution (see Note 7). Combine the mixture in the tube with the $50 \mu \mathrm{L}$ DMSO solution containing the guide-DNA from the last step. Mix well and incubate the mixture at room temperature and $500 \mathrm{rpm}$ for $30 \mathrm{~min}$. Add $8.0 \mu \mathrm{L}$ of ethylene diamine and incubate for $30 \mathrm{~min}$. Add $1.0 \mathrm{~mL}$ of $\mathrm{LiClO}_{4}$ acetone solution. Mix thoroughly and store at $-80^{\circ} \mathrm{C}$ for $3 \mathrm{~h}$.

3. Take the tube from $-80^{\circ} \mathrm{C}$ and centrifuge at $4^{\circ} \mathrm{C}$ an $\mathrm{d} 16.1 \times 10^{3} \mathrm{rfc}$ for $30 \mathrm{~min}$. Wash the pellet with acetone. Centrifuge at $4^{\circ} \mathrm{C}$ and $16.1 \times 10^{3} \mathrm{rfc}$ for $5 \mathrm{~min}$. Remove the supernatant carefully with a pipette. Dry the pellet in vacuum at room temperature for $10 \mathrm{~min}$. Dissolve the dried pellet in $10 \mu \mathrm{L}$ of potassium phosphate buffer. Referred to as Solution II.

\subsection{Preparation of the reactive strand (dRS), Solution III}

1. Mix $2.0 \mu \mathrm{L}$ of Solution I with $10.0 \mu \mathrm{L}$ of Solution II in a $1.5 \mathrm{~mL}$ tube. Mix gently. Incubate the mixture at room temperature and $500 \mathrm{rpm}$ for $1 \mathrm{~h}$. Add $1.0 \mu \mathrm{L}$ of $\mathrm{NaCl}$ solution and 1.0 $\mathrm{mL}$ of ethanol. Mix the solution well and store it at $-80^{\circ} \mathrm{C}$ for $3 \mathrm{~h}$.

2. Take the tube from $-80^{\circ} \mathrm{C}$ and centrifuge at $4^{\circ} \mathrm{C}$ and $16.1 \times 10^{3} \mathrm{rfc}$ for $30 \mathrm{~min}$. Remove the supernatant and dry the precipitate in vacuum at room temperature for $10 \mathrm{~min}$. Dissolve the dried pellet in $25 \mu \mathrm{L}$ of NaOAc buffer $(50 \times)$. Place the solution on ice (see Note 8). Referred to as Solution III.

\section{4 dRS-hybridized RNA, Solution IV.}

1. Prepare $80 \mu \mathrm{L}$ of the btuB riboswitch sample $(\sim 36.0 \mu \mathrm{M})$ in NaOAc buffer $(1 \times)$ and add 30 $\mu \mathrm{L}$ of dHS solutions (Fig. 2, see Note 9). Mix gently. Heat the mixture at $70^{\circ} \mathrm{C}$ for $5 \mathrm{~min}$ and 
cool down slowly to room temperature for about 30 min without agitation to allow for hybridization of the dHS. Centrifuge at low speed shortly to recollect any condensated solvent from the lid.

2. Add $25 \mu \mathrm{L}$ of Solution III. Mix gently. Incubate the solution at room temperature for $10 \mathrm{~min}$ without agitation to allow for hybridization of the $\mathbf{d R S}$ and place it on ice before continuing to the next step (see Note 8). Referred to as Solution IV.

\subsection{Crude functionalized RNA, Solution V.}

1. Add $15 \mu \mathrm{L}$ of $\mathrm{NalO}_{4}$ solution to Solution IV of the previous step. Incubate the mixture at room temperature and $500 \mathrm{rpm}$ for $90 \mathrm{~min}$ (see Note 10). Add $30 \mu \mathrm{L}$ of ethylene glycol solution and mix well. Incubate at room temperature and $500 \mathrm{rpm}$ overnight (see Note 11). Stop the reaction by applying the solution to a NAP-5 column and elute the sample with water.

2. Lyophilize the eluted sample solution overnight, giving white spongy precipitate. Spin down the precipitate to the bottom of the tube. Add a minimal volume of water or potassium phosphate buffer to dissolve the spongy precipitate (see Note 12). Store the product at -20 ${ }^{\circ} \mathrm{C}$ or keep it on ice if the purification will be carried out the same day. Referred to as

\section{Solution V.}

\subsection{Purification of functionalized RNA, Solution VI.}

1. Add one volume equivalent of FLB to Solution V. Mix gently. Load the mixture on a $5 \%$ denaturing PAGE (see Note 13 and 14). Run the PAGE at 10-20 $\mathrm{W}$ at $4{ }^{\circ} \mathrm{C}$ for about $1.5 \mathrm{~h}$ or before the lower marker-dye migrates to the bottom edge of the gel. Check carefully not to lose RNA.

2. Use a spatula to pry the glass plates and move the gel body to a plastic wrap. Place the gel body under a UV lamp to visualize (R)NA bands. Cut out the bands that correspond to the correct size (see Note 15). Collect the gel pieces in clean $1.5 \mathrm{~mL}$ tubes. To each tube, 
add $800 \mu \mathrm{L}$ soaking buffer. Fix the tubes on a low-speed rotary at $4{ }^{\circ} \mathrm{C}$ for $2.5 \mathrm{~h}$ and gently mix every 20 min.

3. Centrifuge the tubes containing the soaked mixture at $4{ }^{\circ} \mathrm{C}$ and $16.1 \times 10^{3} \mathrm{rfc}$ for $30 \mathrm{~min}$. Collect the supernatant to new $1.5 \mathrm{~mL}$ tubes (see Note 16) keeping the volume of the supernatant in each tube below $350 \mu \mathrm{L}$. Add three volume equivalents ice cold ethanol to each tube. Mix well and store it at $-80^{\circ} \mathrm{C}$ overnight.

4. Take the tubes from $-80^{\circ} \mathrm{C}$ and centrifuge the precipitated sample at $4{ }^{\circ} \mathrm{C}$ and $16.1 \times 10^{3}$ rfc for 30 min. Remove the supernatant and dry the precipitate in vacuum at room temperature for $5 \mathrm{~min}$. Dissolve the pellet in water or buffer as needed. Referred to as Solution VI (see Note 17).

\subsection{3'-terminal labeled RNA, Solution VII}

1. Prepare $25 \mu \mathrm{L}$ of Solution VI (RNA $\sim 25 \mu \mathrm{M})$ in TEAA buffer in a $1.5 \mathrm{~mL}$ tube. Mix with 5.0 $\mu \mathrm{L}$ formamide and 5.0 $\mu \mathrm{L}$ DMSO. Flush the solution with argon for $1 \mathrm{~min}$ (see Note 18). Add $2.0 \mu \mathrm{L}$ of argon-flushed Cy3-hydrazide solution (see Note 19) [16]. Mix gently and incubate the solution in the dark at room temperature and $500 \mathrm{rpm}$ overnight.

2. To stop the reaction add $1.0 \mathrm{~mL}$ of ethanol to the tube. Mix gently and store at $-80^{\circ} \mathrm{C}$ for 3

h. Take the tube from $-80^{\circ} \mathrm{C}$ and centrifuge at $4{ }^{\circ} \mathrm{C}$ and $16.1 \times 10^{3} \mathrm{rfc}$ for $30 \mathrm{~min}$. Remove the supernatant and wash with $200 \mu \mathrm{L}$ ice cold ethanol. Centrifuge again for 10 min (see Note 20) and dry the pellet under vacuum at room temperature for $5 \mathrm{~min}$. Dissolve the pellet in $25 \mu \mathrm{L}$ TEAA buffer. Referred to as Solution VII (see Note 21).

\subsection{Dual-color labeled RNA, Solution VIII}

1. Mix $25 \mu \mathrm{L}$ of Solution VII with $10 \mu \mathrm{L}$ formamide, $55 \mu \mathrm{L}$ DMSO, $2.0 \mu \mathrm{L}$ Cy5-azide solution (see Note 21), and $10 \mu \mathrm{L}$ ascorbic acid solution (see Note 22). Flush the mixture with argon for $1 \mathrm{~min}$ (see Note 18) and add $10 \mu \mathrm{L} \mathrm{Cu-TBTA}$ solution. Flush the mixture with argon for 1 min and incubate it in the dark at $25^{\circ} \mathrm{C}$ and $500 \mathrm{rpm}$ overnight. 
2. To stop the reaction add $1.0 \mathrm{~mL}$ of ethanol to the tube. Mix gently and store the mixture at $-80{ }^{\circ} \mathrm{C}$ for $3 \mathrm{~h}$. Take the tube from $-80^{\circ} \mathrm{C}$ and centrifuge at $4{ }^{\circ} \mathrm{C}$ and $16.1 \times 10^{3} \mathrm{rfc}$ for 30 $\min$. Remove the supernatant, wash with $200 \mu \mathrm{L}$ ice cold ethanol and centrifuge again for 10 min (see Note 20). Dry the pellet in vacuum at room temperature for $5 \mathrm{~min}$. Dissolve the pellet in water and apply it to a NAP-5 desalting column (see Note 23). Elute with water and lyophilize overnight (see Note 12).

3. Purify the lyophilized product in a 5\% denaturing PAGE (see Note 24) following the same protocol as in 3.6 (see Note 25). Dissolve the recovered RNA in $20 \mu \mathrm{L}$ water or potassium phosphate buffer. Referred to as Solution VIII.

Characterize the dual-color labeled btuB riboswitch in comparison with the non-labeled one in a $10 \%$ denaturing PAGE (Fig. 4, see Note 26).

\subsection{Reverse transcription stop assay}

For a labeling site at the base-paired region, $\boldsymbol{A}_{213}$ (Fig. 5a, see Note 27)

1. Mix $2.0 \mu \mathrm{L}$ of Solution VIII (RNA $~ 1.0 \mu \mathrm{M}$, see Note 28 ) with $2.0 \mu \mathrm{L}$ of the ${ }^{32} \mathrm{P}$-labeled primer solution (see Note 29) and $4.0 \mu \mathrm{L}$ of $\mathrm{dNTP}_{\text {mix. }}$ Mix gently. Heat at $70{ }^{\circ} \mathrm{C}$ for $5 \mathrm{~min}$ and cool on ice for $1 \mathrm{~min}$.

2. Add $1.0 \mu \mathrm{L}$ of RNAse inhibitor and $2.0 \mu \mathrm{L}$ of AMV reverse transcriptase (RT) buffer. Mix gently and incubate at $42{ }^{\circ} \mathrm{C}$ for $1 \mathrm{~min}$.

3. Add $1.0 \mu \mathrm{L}$ of AMV RT and mix gently. Incubate the sample at $42{ }^{\circ} \mathrm{C}$ for $1 \mathrm{~h}$ without agitation.

For a labeling site at the internal loop, $A_{35}$ (Fig. 5b, see Note 27).

1. Mix 1.0 $\mu \mathrm{L}$ of Solution VIII (RNA 1.0 $\mu \mathrm{M}$, see Note 28) with $1.0 \mu \mathrm{L}$ of the ${ }^{32} \mathrm{P}$-labeled primer (see Note 29) and $4.0 \mu \mathrm{L}$ of $\mathrm{dNTP}_{\text {mix. }}$ Mix gently. Heat at $70{ }^{\circ} \mathrm{C}$ for $5 \mathrm{~min}$. Place on ice for $5 \mathrm{~min}$. 
2. Add $1.0 \mu \mathrm{L}$ of Rnase inhibitor, $1.0 \mu \mathrm{L}$ of DTT and 3.0 $\mu \mathrm{L}$ of SuperScript III RT buffer. Mix gently and incubate at $52{ }^{\circ} \mathrm{C}$ for $1 \mathrm{~min}$.

3. Add $1.0 \mu \mathrm{L}$ of SuperScript III RT and mix gently. Incubate the sample at $52{ }^{\circ} \mathrm{C}$ for $1 \mathrm{~h}$ without agitation.

4. For both cases, stop the reactions by heating the sample to $90^{\circ} \mathrm{C}$ and incubate for $5 \mathrm{~min}$. Then, add one equivalent volume of FLB to the sample. Load the sample directly on a $18 \%$ denaturing PAGE gel. After drying, the gel was exposed to a phosphor imaging screen overnight and scanned the following day (see Fig. 5 and Note 30).

\subsection{Sample annealing and purification for smFRET measurements}

1. Mix $1.0 \mu \mathrm{L}$ of Solution VIII (RNA $\sim 1.0 \mu \mathrm{M}$ ) with $1.0 \mu \mathrm{L}$ biotin-DNA oligonucleotides (see Note 31), $0.5 \mu \mathrm{L} \mathrm{KCl}$ solution, $2.0 \mu \mathrm{L}$ folding buffer $(5 \times$, see Note 32$)$ and $4.5 \mu \mathrm{L}$ water and mix gently.

2. RNA annealing/folding: Incubate the sample at $70{ }^{\circ} \mathrm{C}$ for $5 \mathrm{~min}$; incubate at room temperature for $3 \mathrm{~min}$ and add $1.0 \mu \mathrm{L} \mathrm{MgCl} 2$ solution. Mix gently (see Note 33 ). Incubate the sample solution at $37^{\circ} \mathrm{C}$ for $30 \mathrm{~min}$, then, at room temperature for another $30 \mathrm{~min}$. Low-speed centrifuge the sample tube to recollect any condensated solvent from the lid.

The number of double-labeled molecules immobilized in a TIRF experiment can be increased by applying an additional native PAGE purification step of the pre-annealed RNA sample carrying the biotin-DNA.

3. Native PAGE (6\%) purification: load the sample and run the gel at $4{ }^{\circ} \mathrm{C}$ and $10-20 \mathrm{~W}$ for 100 min (see Note 34).

4. Pry the gel plates with a spatula. Cut out the gel bands with co-localized fluorescence emission of Cy3 and Cy5 (see Note 25). Soak the gel pieces and precipitate the hybridized RNAs following the same protocol as in 3.6. 
5. The precipitated sample is re-annealed under the same condition as described in $\mathbf{3 . 1 0}$, giving $10 \mu \mathrm{L}$ of the sample solution diluted with the folding buffer containing the desired $\mathrm{Mg}(\mathrm{II})$ concentration for the smFRET measurements (see Note 35).

\section{Notes}

1. The synthesis of compounds $\mathbf{1}, \mathbf{2}, \mathbf{3}$, and $\mathbf{4}$ for the RG (see Fig. 1) was described previously [13]. Complementary notes are listed here: (i) Reaction between compound $\mathbf{1}$ and dry methanol should be strictly controlled in a water-free environment. The incubation should last no longer than $15 \mathrm{~min}$. Both the presence of water and longer incubation times can lead to byproducts. To this end, we recommend carrying out this reaction with the subsequent methanol evaporation on a rotary evaporator. (ii) To completely remove the methanol, we recommend adding $5 \mathrm{~mL}$ of dry $\mathrm{CH}_{2} \mathrm{Cl}_{2}$ (distilled over $\mathrm{CaH}_{2}$ ) to the residue and to co-evaporate both, methanol and $\mathrm{CH}_{2} \mathrm{Cl}_{2}$. Repeating the purification step twice yields the pale-yellow oil of compound 2. (iii) Compound $\mathbf{2}$ is very sensitive under ambient condition. Use it immediately for the next reaction step or store it at $-20^{\circ} \mathrm{C}$ after drying under high vacuum. However, longtime storage is not recommended. (iv) In general, all compounds should be stored at $-20^{\circ} \mathrm{C}$ to avoid degradation. We particularly recommend drying the RG precursor under high vacuum and in an ice/ $\mathrm{H}_{2} \mathrm{O}$ bath to remove water as much as possible. The freshly synthesized RG precursor is usually a viscous oil. Upon storage at $-20{ }^{\circ} \mathrm{C}$ for months, crystals or solids can form.

2. As the reaction proceeds, crystals or precipitates can be observed at the bottom of the tube.

3. Activated RG easily degrades at room temperature and therefore should always be kept on ice.

4. Design criterions for the guide-DNA of the dRS (Fig. 1b): (i) A phosphorylated terminal end of the guide-DNA is required for the addition reaction of ethylene diamine. (ii) The guide DNA has to bind to the RNA in such a way that the modified terminal base-pair (position $\boldsymbol{n}$, see Fig. 1b) locates one or two ribonucleotides up- or downstream (depending on the $5^{\prime}$ or $3^{\prime}$ modification of the guide-DNA with the RG) of the labeling site (position $\boldsymbol{n}+2$, see Fig. $1 \mathrm{~b}$ ). 
(iii) Adenine and cytosine shall not be placedat the phosphorylated terminal end of the guideDNA to prevent its self-modification. (iv) The size of the guide-DNA should not exeed10 nt to allow a rational design of the dHS but should have a GC content greater than $50 \%$ to ensure specific and tight binding to the RNA strand.

5. Before use, heat the $\mathrm{CTAB}$ solution at $60^{\circ} \mathrm{C}$ for $30 \mathrm{~min}$ or until the solid is completely dissolved.

6. Store at $4{ }^{\circ} \mathrm{C}$. Solutions should be prepared freshly before use.

7. A bright yellow solution should be observed after the three chemicals are mixed. If the solution is only light yellow or colorless, discard it, validate the used chemicals and repeat the reaction by mixing again the three chemicals.

8. To prevent degradation of $\mathbf{d R S}$, Solution III is recommended to be prepared immediately before use and should always be kept on ice.

9. dHSs are particularly helpful for labeling ribonucleotides which are base-paired and/or shielded by secondary and/or tertiary structural elements. Rationally designed dHSs that bind up- or downstream of the RNA sequence complementary to the dRS can enhance the hybridization of the dRS to the RNA at moderate temperatures and thus increase the overall labeling efficiency. An additional benefit is that hybridization can be performed at moderate temperature, with reduces degradation of the RG.

Design of the dHSs mainly considers factors such as the RNA fold, the GC content, and the predicted melting temperature of the respective dHS/RNA hybrid. If the RNA fold is unknown, secondary structure predictions should be consulted for dHS and dRS design. Herein, we show two examples in the context of the btuB riboswitch in which implementation of suitable dHS sequences has a pronounced effect. For the modification of $A_{35}$ (Fig. 2), two helper sequences are designed to mask short segments on both sides of the target nucleotide in order to open up the stem loop temporarily to allow $\mathbf{d R S}$ hybridization. In the absence of any dHS only $60 \%$ of the dRS binds to the RNA at room temperature. In contrast, prior incubation 
with one equivalent of each dHSs increases the binding efficiency of the $\mathbf{d R S}$ to over $95 \%$ at ambient temperature. By comparison, temperature induced unfolding in absence of any $\mathbf{d H S}$ shows only about $70 \%$ hybridization efficiency. For $A_{213}$ (Fig. 2 ) the effect is even more drastic. Only about $20 \%$ of the dRS anneal to the RNA in the absence of dHS at room temperature, whereas the addition of one equivalent of each dHS leads to $\sim 75 \%$ bound $\mathbf{d R S}$. Again, thermal melting without $\mathbf{d H S}$ produces no more than $50 \%$ hybridized strands.

10. We validated that $90 \mathrm{~min}$ is the optimal incubation time with sodium periodate to convert the reactive group to an aldehyde $[13,14]$. Longer times would result in over-oxidation of the reactive group to an inactive ketone. At the same time sodium periodate oxidizes the 3'terminal ribose unit of the RNA to a di-aldehyde moiety required for biorthogonal labelling. Again, we validated that 90 min of incubation is sufficient for this reaction.

11. Ethylene glycol is used as a reducing agent to quench sodium periodate. Overnight incubation is acceptable. A longer incubation time may induce RNA degradation.

12. If the volume of the eluted sample does not exceed $100 \mu \mathrm{L}$, the lyophilization step can be omitted.

13. This step is to purify the functionalized RNA from dRS, dHSs and their derivatives and potentially degraded RNA fragments with denaturing PAGE. The percentage of acrylamide varies depending on the molecular weight differences between the RNA and the DNA oligonucleotides. Roughly, we recommend using a low percentage of e.g. $5 \%$, because of the increased RNA-soaking efficiency. Importantly, it is essential to remove the DNA oligonucleotides before proceeding to the subsequent steps. Without PAGE purification, we observed a dramatic degradation of the RNA after the subsequent dye-coupling reactions. We speculate binding of dRS, dHSs and/or their derivatives to the RNA may result in RNA conformations that are prone for degradation under the conditions of the dye-coupling reactions.

14. Load the sample into multiple gel wells as needed, since the total volume including FLB is usually larger than the volume of a single well. 
15. Load the non-modified RNA construct as a reference. Ensure that the loaded RNA concentration allows for the visualization via UV shadowing.

16. Avoid touching the gel pieces with the tip of the pipette. Otherwise, unintendedly collected gel pieces/substances will co-precipitate with the RNA upon ethanol precipitation.

17. We recommend measuring the fluorescence emission profile of Solution VI before proceeding to the subsequent dye-coupling steps. An emission peak around $415 \mathrm{~nm}$ upon excitation at $275 \mathrm{~nm}$ (or $308 \mathrm{~nm}$ ) is indicative for a successful internal RNA modification (Fig. $3)$.

18. Be attentive not to blow the sample out of the tube. We recommend adjusting the argon flow rate with a blank test sample in a $1.5 \mathrm{~mL}$ tube containing water or TEAA buffer of the same volume as the sample.

19. Because the 3'-dialdehyde is generally more reactive than the alkyne, we recommend performing the 3'-terminal dye-coupling prior to the internal dye-coupling. As we observed that Cy3 is prone to photo-bleaching and has a reduced re-orientation probability when attached to internal sites of the RNA, we used Cy3 for the 3'-terminal end. In addition, we recommend using sulfonated carbocyanine dyes due to their increased water-solubility and reduced interaction with the RNA-backbone owing to their negative charge [21].

20. Ethanol washing can be repeated until the supernatant becomes nearly colorless.

21. Compared to Cy3, Cy5 is less likely to photo-bleach when labeled at internal sites of RNAs.

22. Ascorbic acid solution must be prepared freshly before use as it is easily oxidized if exposed to air.

23. A NAP-5 desalting column removes free dyes efficiently and is fast compared to multiple rounds of ethanol precipitation.

24. For "biophysical" measurements, the denaturing PAGE purification step is mandatory, as it completely removes trace amounts of free dyes. Be sure the sample was purified by 
ethanol precipitation and NAP desalting column to remove most excess of dyes before loading to the PAGE gel.

25. We used a Typhoon scanner with fluorescence imaging capabilities to locate the target bands. The fluorescence detection is much more sensitive than UV shadowing.

26. We estimate that about $5 \%$ of the total RNA after PAGE purification is dual-color-labeled based on UV-vis absorption spectra [12]. This amount is sufficient for single-molecule fluorescence spectroscopy. We used higher percentage PAGE to get denser bands enabling UV shadowing for lower concentrated RNA samples (Fig. 4).

27. Reverse transcription stop assay is employed to probe the internal fluorophore-labeling sites, in which a primer anneals downstream of the putative labeling site and is extended by a reverse transcriptase (Fig. 5). In our experiments, reverse transcriptase exhibits varied susceptibility to be stalled by the fluorophore-labeled ribonucleotides depending on the different positions. We describe the optimized protocols of AMV reverse transcriptase that is best for the base-paired labeling site $\left(A_{213}\right)$ and SuperScript III reverse transcriptase that is best for the labeling site $\left(A_{35}\right)$ within an internal loop.

28. In order not to waste the precious dual-color labeled RNA (Solution VIII), the single internally labeled sample was used skipping the 3'-terminal coupling step.

29. Importantly, the ${ }^{32} \mathrm{P}$-marked primer should be shorter than 20 nucleotides and should be designed in such a way that it binds with its 3'-terminus less than 10 nucleotidesdownstream of the putative labeling site of the RNA (Fig. 5). In this way, we were able to separate the differently extended ${ }^{32} \mathrm{P}$-marked primers at a 1 -nucleotide resolution on a high percentage (18\%) denaturing PAGE.

30. Be aware that the reverse transcriptase is not stalled at the presumed labeling site but inserts one additional nucleotide before stopping and releasing the ${ }^{32} \mathrm{P}$-marked primer (Fig. 5). This effect is known as delayed chain termination (CT) [22]. 
31. The biotin-carrying DNA oligonucleotide is used to immobilize the RNA molecule on the quartz surface via biotin-streptavidin interaction. The oligonucleotide is designed to bind to the 5'-elongated region of the RNA and not to interfere with the RNA's native fold [19]. We recommend adding a two-fold excess of biotin-DNA primer to ensure that all dual-color labeled RNAs ( 5\%, see Note 26$)$ are hybridized. The non-hybridized biotin-labeled will be removed by the subsequent Native PAGE purification which also removes the degraded RNAs and other impurities (see Note 34).

32. The precise composition of the folding buffer depends on the folding conditions of the particular RNA studied.

33. Addition of $\mathrm{Mg}(\mathrm{II})$ is required for formation of the tertiary structure.

34. The Native PAGE purification is not mandatory. However, we recommend its application as otherwise the excess of biotin-labeled primers that is not hybridized to the RNA would block the Streptavidin binding sites (see Fig. 6), reducing the number of immobilized RNA molecules.

35. Empirically, we started with the $10^{5}$-fold dilution (100 pM) of the re-annealed doublelabeled RNA sample for single-molecule TIRF imaging. Adjustments may be necessary depending on the RNA concentration recovered from the Native PAGE purification and the labeling efficiency.

Application notes:

1. Site-specific biorthogonal fluorescent labeling of RNA is of particular interest for FRET studies, as this method demands labeling with two fluorophores. Further details on single molecule FRET or FRET gels can be found elsewhere [12, 23, 24].

2. The labeling scheme is not limited to fluorescent entities, but can be adapted to any reporter molecule such as spin labels for EPR studies [25-27].

\section{Acknowledgement}


We thank Anna Zemann, Nora Grundmann, and Dr. Sofia Gallo for their valuable feedback regarding the synthesis of the RG precursor. Financial support from the Swiss National Science Foundation [to E.F. and R.K.O.S.], the European Research Council [ERC to R.K.O.S.], SystemsX.ch [to R.K.O.S.], the UZH Forschungskredit [FK-14-096, FK-15-095 to R.B.], the UZH Stiftung für wissenschaftliche Forschung [to R.K.O.S. and R.B.], the University of Zurich and the SBFI [COST Action CM1105 to E.F. and R.K.O.S] is gratefully acknowledged. Funding for open access charge: University of Zurich.

\section{References}

1. Rao H, Tanpure AA, Sawant AA, Srivatsan SG (2012) Enzymatic incorporation of an azide-modified UTP analog into oligoribonucleotides for post-transcriptional chemical functionalization. Nat Protoc 7: 1097-1112

2. Lavergne T, Lamichhane R, Malyshev DA, Li Z, Li L, Sperling E et al (2016) FRET characterization of complex conformational changes in a large 16S ribosomal RNA fragment site-specifically labeled using unnatural base pairs. ACS Chem Biol 11: 13471353

3. Seidu-Larry S, Krieg B, Hirsch M, Helm M, Domingo O (2012) A modified guanosine phosphoramidite for click functionalization of RNA on the sugar edge. Chem Commun 48: $11014-11016$

4. Liu Y, Holmstrom E, Zhang J, Yu P, Wang J, Dyba MA et al (2015) Synthesis and applications of RNAs with position-selective labelling and mosaic composition. Nature 522: $368-372$

5. Lang K, Micura R (2008) The preparation of site-specifically modified riboswitch domains as an example for enzymatic ligation of chemically synthesized RNA fragments. Nat Protoc 3: $1457-1466$

6. Smith GJ, Sosnick TR, Scherer NF, Pan T (2005) Efficient fluorescence labeling of a large RNA through oligonucleotide hybridization. RNA 11: 234-239 
7. Steiner M, Karunatilaka KS, Sigel RKO, Rueda D (2008) Single-molecule studies of group II intron ribozymes. Proc Natl Acad Sci U S A 105: 13853-13858

8. Schmitz AG, Zelger-Paulus S, Gasser G, Sigel RKO (2015) Strategy for internal labeling of large RNAs with minimal perturbation by using fluorescent PNA. ChemBioChem 16: $1302-1306$

9. Büttner L, Javadi-Zarnaghi F, Höbartner C (2014) Site-specific labeling of RNA at internal ribose hydroxyl groups: Terbium-assisted deoxyribozymes at Work. J Am Chem Soc 136: $8131-8137$

10. Plotnikova A, Osipenko A, Masevičius V, Vilkaitis G, Klimašauskas S (2014) Selective covalent labeling of miRNA and siRNA duplexes using HEN1 methyltransferase. J Am Chem Soc 136: 13550-13553

11. Baum DA, Silverman SK (2007) Deoxyribozyme-catalyzed labeling of RNA. Angew Chem Int Ed 46: 3502-3504

12. Zhao M, Steffen FD, Börner R, Schaffer MF, Sigel RKO, Freisinger E (2018) Site-specific dual-color labeling of long RNAs for single-molecule spectroscopy. Nucleic Acids Res 46: e13

13. Egloff D, Oleinich IA, Freisinger E (2015) Sequence-specific generation of $1, N^{6}$ ethenoadenine and 3,N4-ethenocytosine in single-stranded unmodified DNA. ACS Chem Biol 10: 547-553

14. Egloff D, Oleinich IA, Zhao M, König SLB, Sigel RKO, Freisinger E (2016) Sequencespecific post-synthetic oligonucleotide labeling for single-molecule fluorescence applications. ACS Chem Biol 11: 2558-2567

15. Fuchs BM, Glockner FO, Wulf J, Amann R (2000) Unlabeled helper oligonucleotides increase the in situ accessibility to $16 \mathrm{~S}$ rRNA of fluorescently labeled oligonucleotide probes. Appl Environ Microbiol 66: 3603-3607 
16. Qin PZ, Pyle AM (1999) Site-specific labeling of RNA with fluorophores and other structural probes. Methods 18: $60-70$

17. Nahvi A, Barrick JE, Breaker RR (2004) Coenzyme $B_{12}$ riboswitches are widespread genetic control elements in prokaryotes. Nucleic Acids Res 32: 143-150

18. Perdrizet GA, Artsimovitch I, Furman R, Sosnick TR, Pan T (2012) Transcriptional pausing coordinates folding of the aptamer domain and the expression platform of a riboswitch. Proc Natl Acad Sci U S A 109: 3323-3328

19. Hilario, E (2004) End Labeling Procedures: An Overview. Molecular Biotechnology 28 (1): $77-80$

20. Gallo S, Furler M, Sigel RKO (2005) In vitro transcription and purification of RNAs of different size. CHIMIA 59 (11): 812-816

21. Steffen FD, Sigel RKO, Börner R (2016) An atomistic view on carbocyanine photophysics in the realm of RNA. Phys Chem Chem Phys 18(42): 29045-29055

22. Sarafianos SG, Clark AD, Tuske S, Squire CJ, Das K, Sheng D et al (2003) Trapping HIV-1 reverse transcriptase before and after translocation on DNA. J Biol Chem 278: $16280-16288$

23. Börner R, Kowerko D, Guiset Miserachs H, Schaffer MF, Sigel RKO (2016) Metal ion induced heterogeneity in RNA folding studied by smFRET. Coord Chem Rev 327-328: $123-142$

24. Ramirez-Carrozzi V, Kerppola T (2001) Gel-based fluorescence resonance energy transfer (gelFRET) analysis of nucleoprotein complex architecture. Methods 25 (1): 3143

25. Kim N-K, Murali A, DeRose V J (2004) A distance ruler for RNA using EPR and sitedirected spin labeling. Chemistry and Biology 11 (7): 939-948. 
26. Esquiaqui J M, Sherman E M, Ye J-D, Fanucci G E (2014) Site-directed spin-labeling strategies and electron paramagnetic resonance spectroscopy for large riboswitches. Methods in Enzymology 549: 287-311.

27. Saha S, Jagtap A P, Sigurdsson S Th (2015) Site-Directed Spin Labeling of RNA by Postsynthetic Modification of 2'-Amino Groups. Methods in Enzymology 563: 397-415 
a
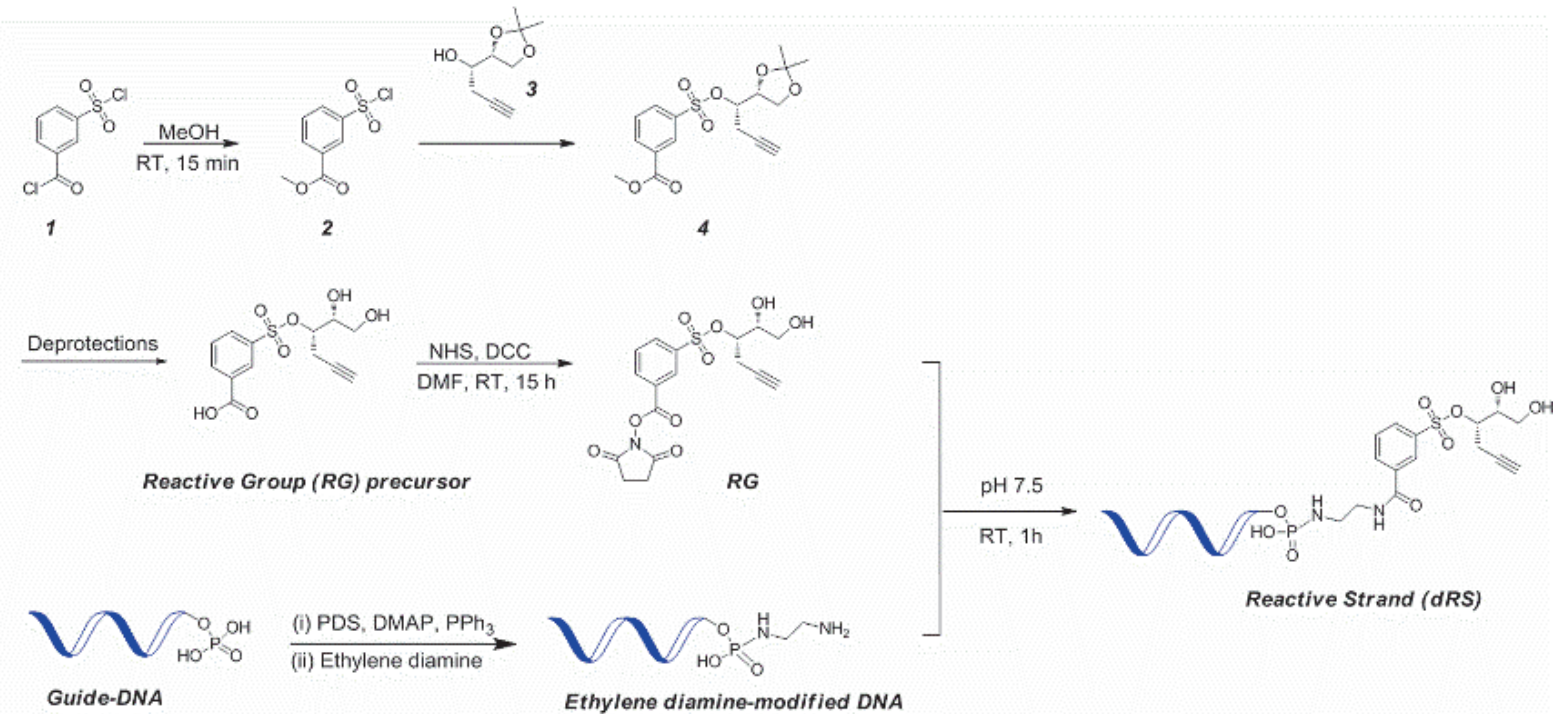

b

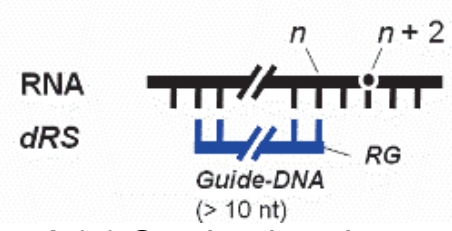

Fig. 1 (a) Synthesis scheme of the reactive group (RG) and the reactive strand (dRS).

Details of the synthesis of compound $\mathbf{1 , 2 , 3}$, and 4 were described previously [14] (b)

Scheme of the dRS binding to the RNA, showing the relative position of the labeling site to the guide-DNA. Adapted from [12]. 


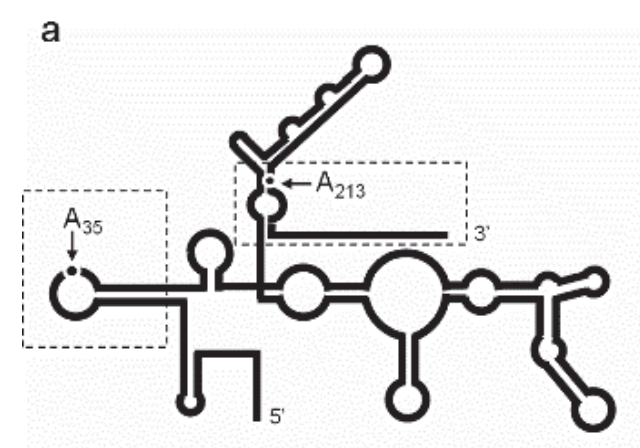

b

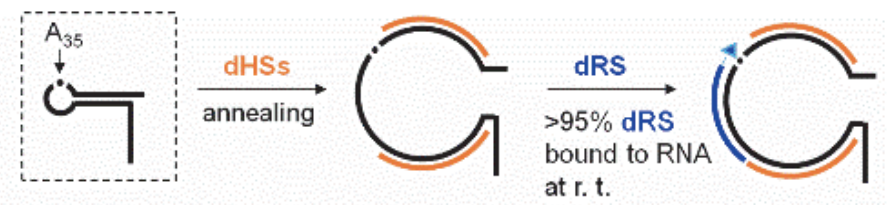

C

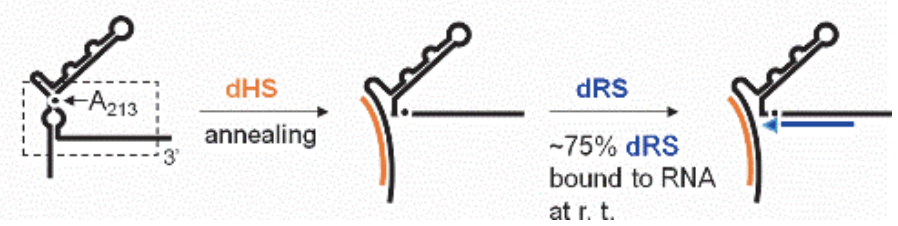

Fig. 2 Scheme of the secondary structure of the btuB riboswitch (a) and the hybridization with $\mathbf{d R S}$ at room temperature assisted by $\mathbf{d H S s}$ for labeling at $A_{35}(\mathbf{b})$ or $A_{213}$ (c). Adapted from [12]. 


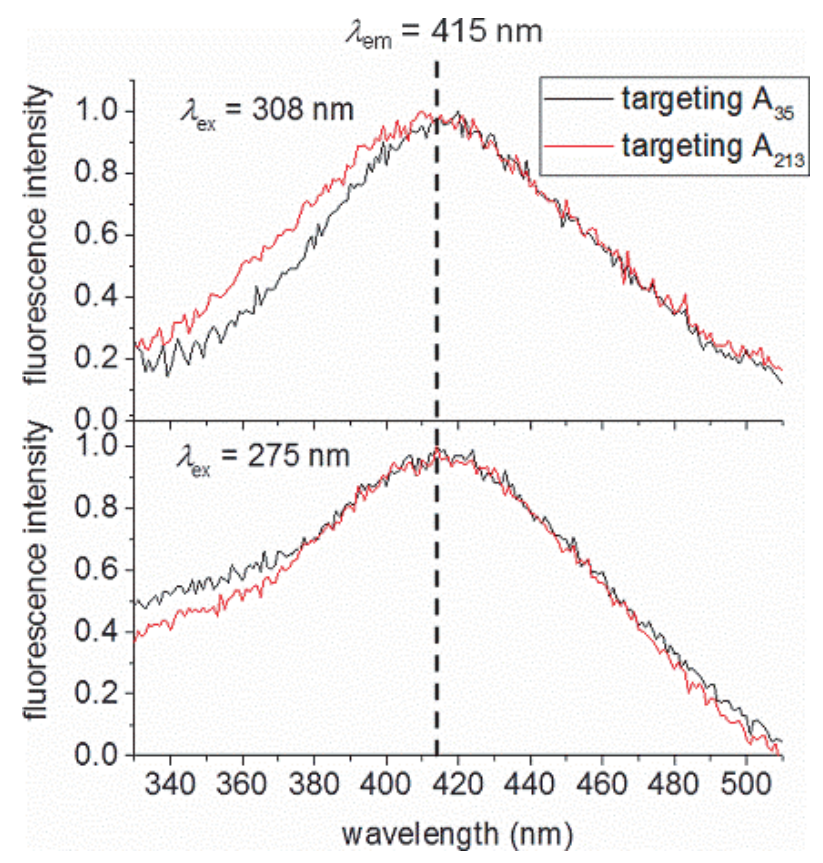

Fig. 3 Normalized fluorescence emission profiles (background subtracted) of the $1, N^{6}$ ethenoadenines at positions $A_{35}$ (black) and $A_{213}$ (red) of Solution VI upon excitation at either $275 \mathrm{~nm}$ or $308 \mathrm{~nm}$. Reproduced from Figure S8 in [12], by permission of Oxford University Press. 


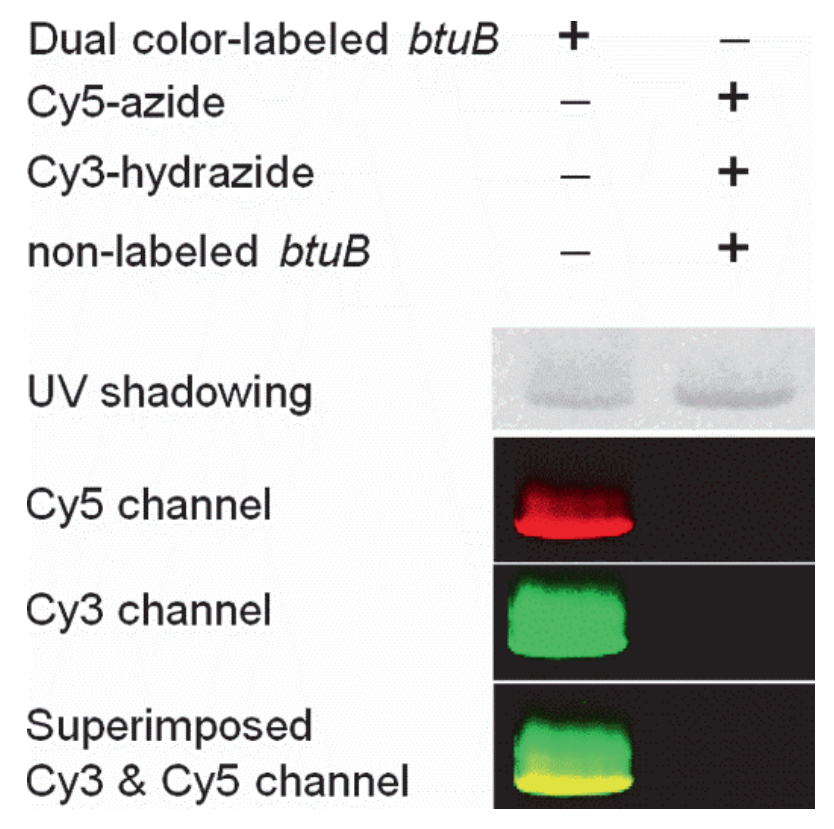

Fig. 4 Probing the double-labelling by a comparative UV shadowing and fluorescence imaging gel. Example denaturing PAGE (10\% w/v, $7 \mathrm{M}$ urea) of the dual-color labeled btuB riboswitch with the Cy3 at the 3'-terminal end and the Cy5 at position $\mathrm{A}_{35}$. Bands on the gel are visualized with both, UV-shadowing ( $\lambda_{\mathrm{ex}}=254 \mathrm{~nm}$, top) and fluorescence imaging (excitation at $635 \mathrm{~nm}$ or $532 \mathrm{~nm}$, respectively, bottom). Color-coded channels show Cy3 (green) and Cy5 (red) emission. Co-localized dyes appear as yellow bands in the superimposed image of both channels. Control lane with the non-modified btuB riboswitch in the presence of both free dyes shows no fluorescence signal. Thus, intercalation of the noncovalently added dyes Cy3 and Cy5 can be excluded. Reproduced and adapted from Figure S12 in [12], by permission of Oxford University Press. 
a

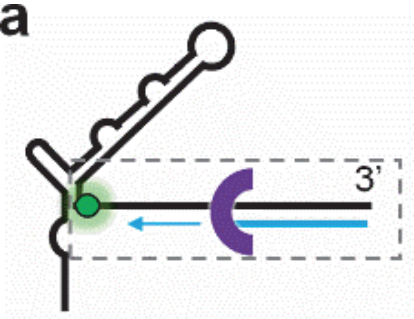

- ${ }^{32}$ P-primer1

fluorophore

AMV RT

S RT stop site
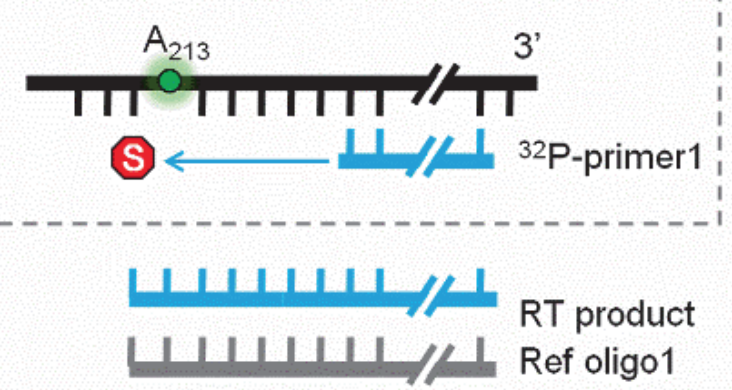

b

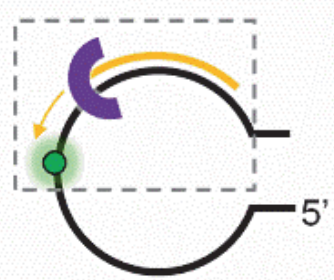

${ }^{32} \mathrm{P}$-primer2

- fluorophore

C Superscript III RT

(S RT stop site

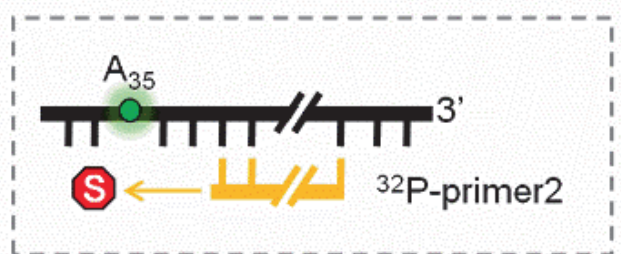

HIII/ / RT product

HLLI// Ref oligo2
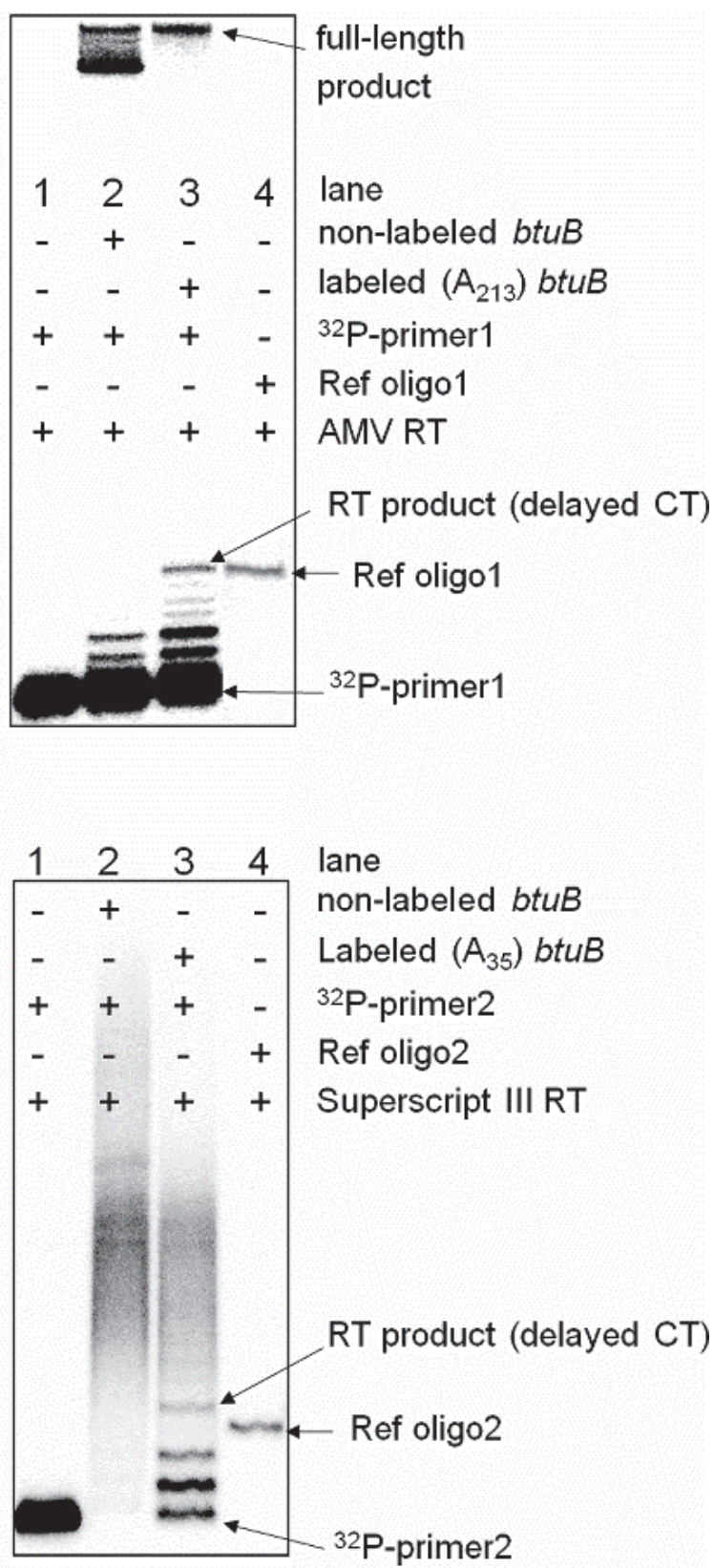

Fig. 5 Probing the internal labeling of $A_{213}(\mathbf{a})$ and $A_{35}$ (b) by reverse transcription. The autoradiograph of the denaturing PAGE footprinting gel (18\% w/v, $7 \mathrm{M}$ urea) shows the original ${ }^{32} \mathrm{P}$-labeled primers (lane 1 ), the extended ${ }^{32} \mathrm{P}$-labeled primers in presence of the non-labeled btuB riboswitch (lane 2), and the internally labeled btuB riboswitch (lane 3). Short DNA oligonucleotides, ${ }^{32} \mathrm{P}$-labeled primer1 + $7 \mathrm{nt}\left(\right.$ Ref oligo1, a) and ${ }^{32} \mathrm{P}$-labeled primer2 $+3 \mathrm{nt}($ Ref oligo1, b) are shown as references (lane 4). Delayed chain termination (CT) is observed which reflects the insertion of one additional nucleotide past the 
modification site [22]. Reproduced and adapted from Figure 2 in [12], by permission of Oxford University Press. 


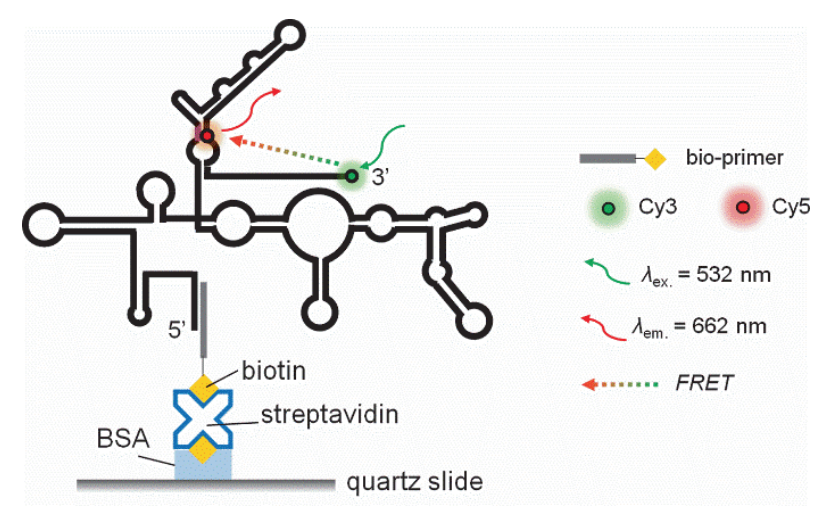

Fig. 6 Schematic depiction of the surface-immobilized dual-color labeled btuB riboswitch, with the Cy3 fluorophore at the 3'-end and the Cy5 fluorophore at position $A_{213}$, located in a double-stranded region of the functional riboswitch. Reproduced and adapted from Figure 13 in [12], by permission of Oxford University Press. 